\title{
CONTROL OF THE MARE'S OESTROUS CYCLE BY PROSTAGLANDINS
}

\author{
W. R. ALLEN AND L. E. A. ROWSON \\ Agricultural Research Council, \\ Unit of Reproductive Physiology and Biochemistry, \\ Animal Research Station, Cambridge*
}

(Received 19th Fanuary 1973)

Several authors have recently demonstrated the luteolytic action of exogenous prostaglandin $\mathrm{F}_{2 \alpha}\left(\mathrm{PGF}_{2 \alpha}\right)$ in various laboratory and domestic animals and there is now ample evidence that $\mathrm{PGF}_{2 \alpha}$ is the uterine luteolytic hormone which terminates the life of the CL in many species (McCracken, 1972; McCracken, Carlson, Glew, Goding, Baird, Gréen \& Samuelsson, 1972). In cattle, Rowson, Tervit \& Brand (1972) showed that an intrauterine (i/u) infusion of $\mathrm{PGF}_{2 \alpha}$ on 2 successive days at any time between the 5th and 16th day of the cycle, induces oestrus 3 days later; they found that for $0.5 \mathrm{mg}$ $\mathrm{PGF}_{2 \alpha}$ to be strongly luteolytic in the cow, the substance must be placed in the uterine horn which is ipsilateral to the ovary containing the active CL. This observation is in accordance with the experiments of Moor \& Rowson (1966), Harrison, Heap \& Linzell (1968) and others, which have indicated that in the sheep, cow and pig, uterine luteolysin passes directly from the uterine horn to the adjacent ovary by way of a local pathway. In the mare, however, unilateral hysterectomy prolongs the life-span of the GL in some animals but not in others, and the proportion in which luteal maintenance occurs seems to be similar irrespective of whether the CL is situated contralateral or ipsilateral to the remaining uterine horn (Ginther \& First, 1971). This finding suggests that uterine luteolysin may reach the ovaries through the general circulation rather than by 'a local pathway' in the mare.

The average length of the oestrous cycle in mares is 22 days. Oestrus is highly variable and may last 3 to 10 days, ovulation occurring 24 to $48 \mathrm{hr}$ before the end of oestrus (Day, 1939). Douglas \& Ginther (1972) have recently demonstrated that a single subcutaneous (s.c.) injection of 1.25 to $10 \mathrm{mg} \mathrm{PGF}$ PG $_{2 \alpha}$ given to a mare on the 6th day after ovulation significantly reduces the length of dioestrus. In the present study, we describe the high luteolytic potency of a new synthetic analogue of PGF $_{2 \alpha}$ (ICI-79939) in the mare.

Fourteen Welsh Pony mares were given the compound ICI-79939 at various stages of dioestrus during a total of forty oestrous cycles. In twenty-nine cycles involving twelve mares, treatment consisted of the infusion of $2 \mathrm{ml}$ of an aqueous solution containing 100,150 or $200 \mu \mathrm{g}$ of the synthetic compound directly into the body of the uterus on 2 successive days. In eleven cycles

* Postal address: Animal Research Station, 307 Huntingdon Road, Cambridge CB3 0JQ. 
involving five mares, a daily intramuscular (i.m.) injection of 300 or $600 \mu \mathrm{g}$ of the compound was given on 2 successive days. The treated mares were teased daily with a stallion so as to detect signs of oestrus and their ovaries were palpated regularly per rectum to determine follicular development and ovulation. Samples of peripheral blood plasma were collected daily, or every other day. They were stored at $-20^{\circ} \mathrm{C}$, and later assayed for total progestagen concentration using a competitive protein-binding assay; in this assay, $1.5 \%$ dog plasma acted as the source of corticosterone-binding globulin and tritiated cortisol ( $40 \mathrm{nCi} / \mathrm{ml}$ ) as the tracer; a small Sephadex column was used for separation of free and bound progestagen fractions. A thin-layer chromatography step to isolate progesterone was not included in the assay and the term 'progestagen' therefore refers to the sum of progestational compounds present in the plasma. Before treatment with ICI-79939, the inter-ovulation interval was determined and serial peripheral plasma progestagen concentrations were measured in all the mares during a normal oestrous cycle.

The results are summarized in Table 1 . All mares treated with a daily dose

Table 1. Response of mares to treatment with ICI-79939

\begin{tabular}{l|rrrrrrrr}
\hline & \multicolumn{7}{c}{ Day of cycle when first treated } \\
\hline & 2 & 3 & 4 & 5 & 6 & 9 & 12 \\
\hline $\begin{array}{l}\text { No. of mares treated } \\
\text { No. of mares which returned to } \\
\text { oestrus within 4 days of first treat- } \\
\text { ment }\end{array}$ & 4 & 5 & 3 & 3 & 11 & 9 & 5 \\
\hline
\end{tabular}

ICI-79939 was given on 2 consecutive days between the 2 nd and 13th days of the oestrous cycle $($ ovulation $=$ Day 0 ).

of 100 to $600 \mu \mathrm{g}$ ICI-79939 on 2 consecutive days, beginning on or after the 4 th day of dioestrus (day of ovulation $=$ Day 0 ), returned to oestrus within 4 days of the 1st day of treatment, irrespective of either the dose or the route of administration (i/u infusion or i.m. injection). However, only three of the five mares which were treated on the 3rd and 4th days of dioestrus returned to oestrus within 4 days, and all four mares which had been treated on the 2nd and 3rd days of dioestrus failed to respond. In general, these results are similar to those obtained in cattle treated with $\mathrm{PGF}_{2 \alpha}$ (Rowson et al., 1972). They indicate that in the mare, as in the cow, the CL is not susceptible to luteolytic attack until it is at least 3 days old.

The majority $(73 \%)$ of mares treated with ICI-79939 returned to oestrus 3 days after the 1st day of treatment (Text-fig. 1a), thus behaving similarly to the mares (Douglas \& Ginther, 1972) and cattle (Rowson et al., 1972) which had been treated with PGF $_{2 \alpha}$. A few mares given ICI-79939 showed oestrus on the 2nd day after the initial treatment and one mare which had been given a single dose of $200 \mu \mathrm{g}$ of the compound by $\mathrm{i} / \mathrm{u}$ infusion on the 12th day of dioestrus displayed clear signs of oestrus the next day. All three of the five mares which returned to oestrus following treatment with ICI-79939 on the 3 rd and 4th days of dioestrus did not show oestrus until 4 days after the 1st day of treatment. 
All the mares which returned to oestrus following the treatment with ICI79939 ovulated normally. The interval between the 1st day of treatment and subsequent ovulation ranged from 7 to 12 days, with a peak at 10 days (Textfig. 1b).

The effect of treatment with ICI-79939 upon progestagen concentrations in the peripheral plasma of mares is illustrated in Text-fig. 2. In the particular animal shown in Text-fig. 2(a), treatment on the 6th and 7th days of dioestrus reduced the normal ovulation interval of 22 days (as determined during the preceding untreated oestrous cycle) to 14 days. Text-figure 2(b) shows the negative effect of treatment with ICI-79939 on the 2nd and 3rd days of dioestrus and also shows the luteolytic action of $600 \mu \mathrm{g}$ of ICI-79939 administered by i.m. injection on 2 consecutive days. At this dose level, the compound

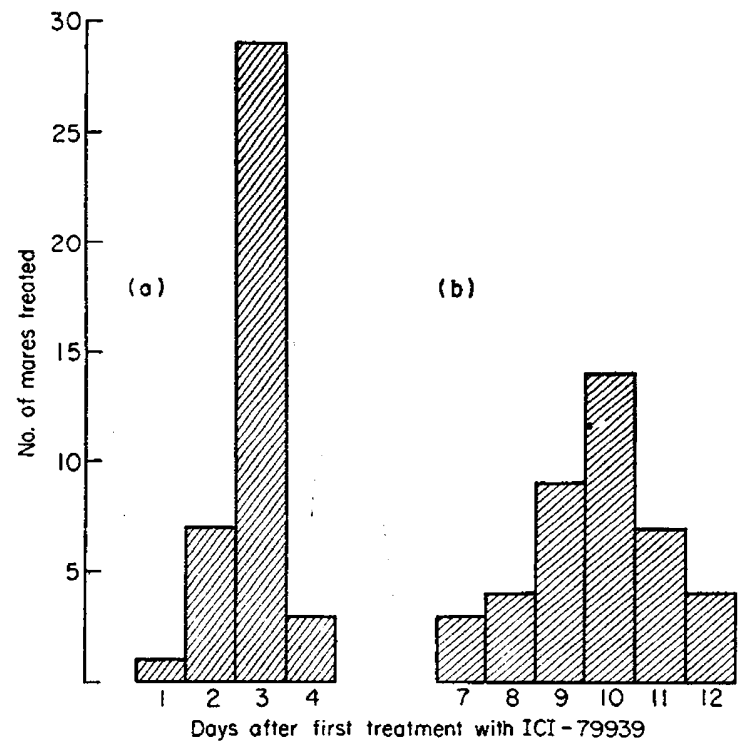

TEXT-FIG. 1. The effect of treatment with IGI-79939 on the onset of oestrus and ovulation in mares. (a) Interval between the first of 2 consecutive days of treatment and the onset of oestrus. (b) Interval between the first of 2 consecutive days of treatment and subsequent ovulation.

showed signs of toxicity, which included sweating in the ventral regions of the neck, chest and abdomen, hypermotility of the gastro-intestinal tract leading to watery diarrhoea, increased rates of pulse and respiration, and mild colic. These symptoms appeared suddenly and most strongly 18 to $22 \mathrm{~min}$ after injection and persisted for 2 to $4 \mathrm{hr}$, steadily decreasing during this time.

Our results indicate that the ICI-79939 analogue of PGF $2 \alpha$ is highly luteolytic in the mare when administered between the 4th and 13th days of dioestrus. This compound exhibits 200 times the luteolytic potency of natural PGF ${ }_{2 \alpha}$ in the hamster and rat (A. L. Walpole, personal communication) and in view of the findings of Douglas \& Ginther (1972), it seems likely that the smallest amount $(100 \mu \mathrm{g})$ used in this study may have been well in excess of the minimal dose of ICI-79939 required to induce luteolysis in the mare. 

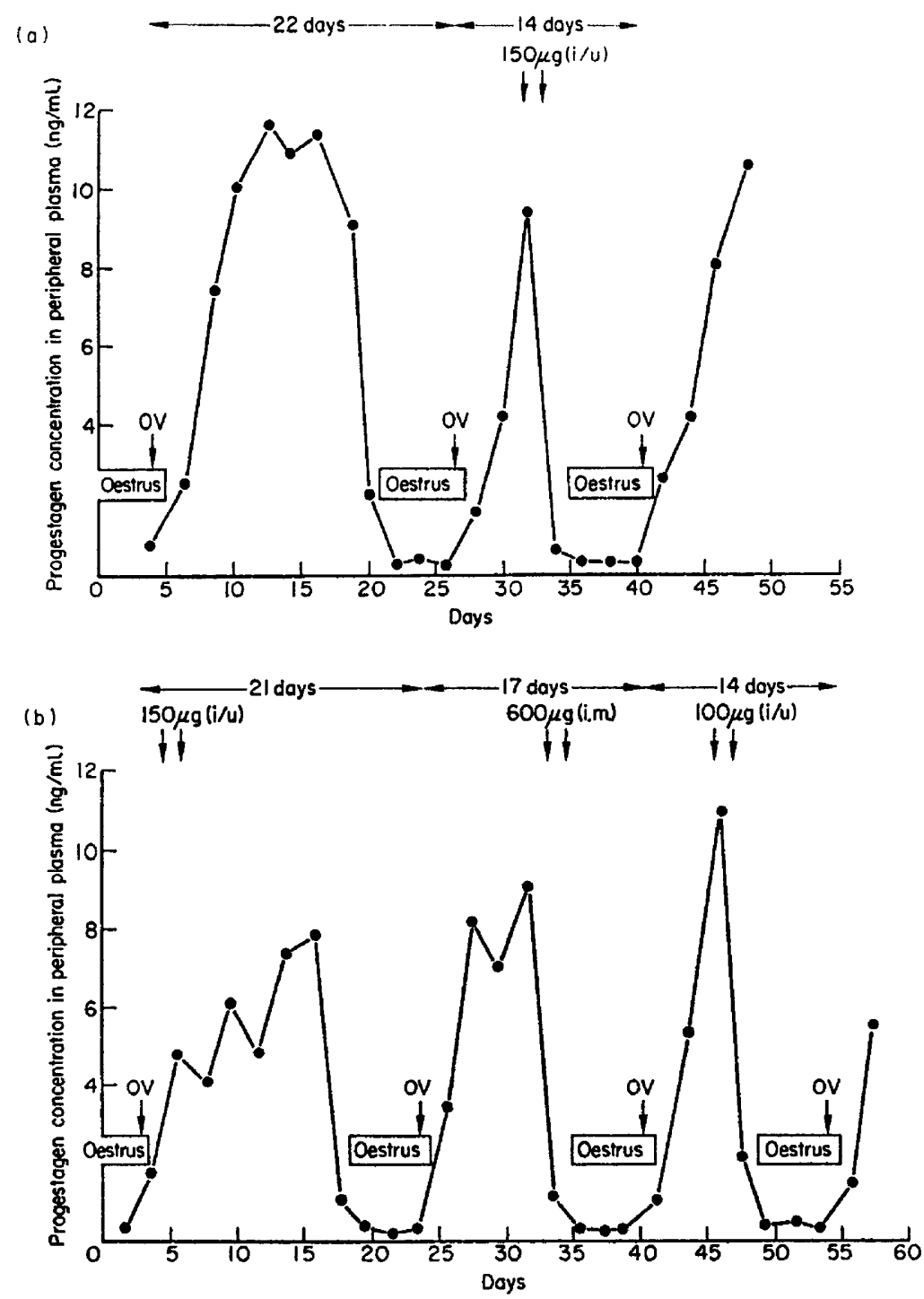

Text-pio. 2. Changes in oestrous cycle length and peripheral plasma progestagen concentrations in mares treated with ICI-79939. (a) Mare given $150 \mu \mathrm{g}$ (i/u) on 6th and 7th days of dioestrous. (b) Mare given (i) $150 \mu \mathrm{g}$ (i/u) on 2nd and 3rd days of dioestrus, (ii) $600 \mu \mathrm{g}(\mathrm{i} / \mathrm{m})$ on 9 th and 10 th days of dioestrus, (iii) $100 \mu \mathrm{g}(\mathrm{i} / \mathrm{u})$ on 4 th and 5 th days of dioestrus. $\mathrm{i} / \mathrm{u}=$ Intrauterine infusion; i.m. = intramuscular injection.

Prostaglandins should prove to be of great value in horse breeding, particularly in those areas of the world where A.I. of mares is practised widely. But even in Thoroughbred mares where A.I. is not permitted by the breed registration authorities, either natural or synthetic prostaglandins should be extremely useful as a means of controlling and shortening the cycle of individual mares. By the planned administration of PGF $_{2 \alpha}$ or its analogue, it should be possible in the future to prevent the awkward situation which often arises in 
large studs when many mares, booked to be covered by a single stallion, come into oestrus simultaneously. Moreover, the thoroughbred breeding season is arbitrarily restricted in length, and therefore, for a variety of reasons, many mares may finish the season after they had been in oestrus on one or two occasions only. It seems that prostaglandins may provide an effective tool for reducing the valuable time which is lost by brood mares as they pass through dioestrus. They may also provide a means of getting rid of persistent CL which prevent the resumption of normal oestrous cycles in some barren and lactating mares and in mares which have suffered resorption or early abortion of a pregnancy.

This work was supported by the Thoroughbred Breeders Association. We are most grateful to Dr A. L. Walpole and Mr M. Cooper of Imperial Chemical Industries, Pharmaceuticals Division, for advice and generous gifts of ICI79939. Professor T. R. R. Mann kindly read the manuscript and Miss M. Crosse and $\mathrm{Mr}$ J. Taylor gave valuable technical assistance.

\section{REFERENGES}

DAy, F. T. (1939) Sterility in the mare associated with irregularities of the oestrous cycle. Vet. Rec. $51,1113$.

Dovglas, R. H. \& GinTHER, O. J. (1972) Effect of prostaglandin $F_{2 a}$ on length of dioestrus in mares. Res. Prostaglandins, 2, 265.

GINTHER, O. J. \& First, N. L. (1971) Maintenance of the corpus luteum in hysterectomized mares. Am. F. vet. Res. 32, 1687.

Harrison, F. A., Heap, R. B. \& Linzell, J. L. (1968) Ovarian function in the sheep after autotransplantation of the ovary and uterus to the neck. F. Endocr. 40, xiii.

McCracken, J. A. (1972) Prostaglandins and luteal regression-a review. Res. Prostaglandins, 1 (3), 1.

MaCracken, J. A., Garison, J. C., Glew, M. E., Goding, J. R., Batrd, D. T., Gréen, K. \& Samuelsson, B. (1972) Prostaglandin $F_{2 \alpha}$ identified as a luteolytic hormone in sheep. Nature, Lond. New Biology, 238, 129.

Moor, R. M. \& Rowson, L. E. A. (1966) Local uterine mechanisms affecting luteal regression in the sheep. F. Reprod. Fert. 11, 307.

Rowson, L. E. A., TeRvir, R. \& BRAND, A. (1972) The use of prostaglandins for synchronization of oestrus in cattle. (Abstract). J. Reprod. Fert.29, 145. 